American Journal of Applied Sciences 3 (8): 1961-1966, 2006

ISSN 1546-9239

(C) 2006 Science Publications

\title{
Improving Mechanical Characteristics of Inverter-induction Motor Drive System
}

\author{
Hussein Sarhan and Rateb Issa \\ Department of Mechatronics Engineering, Faculty of Engineering Technology \\ Al-Balqa' Applied University, Amman, Jordan
}

\begin{abstract}
An inverter-three-phase squirrel-cage induction motor drive system with improved mechanical characteristics is presented. The proposed system provides mechanical characteristics with constant maximum torque or increased maximum torque and reduced slip speed at frequencies below the nominal frequency. The control algorithm is based on the constant volts per hertz principle using two improvement techniques: keeping maximum torque constant or keeping magnetic flux constant. Performance analysis of the system under different operation conditions was provided. For this purpose, a standard state-space model of three-phase squirrel-cage induction motor, with respect to a synchronously rotating $\mathrm{d}-\mathrm{q}$ reference frame was derived. The correctness and validity of the derived model of induction motor was verified. The inverter was considered as a static linear element and modeled through its input-output equation based on the modulation index. Three types of controllers were modeled, simulated and experimentally tested. The results show that both suggested control methods improve the system performance. The slip speed has been decreased and the starting torque and maximum torque have been increased. Controller with constant maximum torque can be used in drive systems working with constant load, while controller with constant flux can be used in drive systems working with constant power.
\end{abstract}

Key words: Induction motor, constant volts per hertz, constant maximum torque, constant flux modeling, simulation

\section{INTRODUCTION}

Induction motor is the most used in industry because of its high robustness, reliability, low cost, high efficiency and good self-starting capability ${ }^{[1]}$. In spite of this popularity, the induction motor has two inherent limitations: (1) The standard motor is not a true constant-speed machine, its full-load slip varies from less than $1 \%$ (in high-horsepower motors) to more than $5 \%$ (in fractional-horsepower motors) and (2) It is not inherently capable of providing variable-speed operation $^{[2,3]}$. These limitations can be solved through the use of smart motor controllers and adjustable speed controllers $^{[4,5]}$. The basic control action involved in a smart motor controller is control of stator voltage at a fixed frequency to accomplish start/stop/braking control and energy efficient operation. The basic control action involved in adjustable speed control of induction motors is to apply a variable frequency variable magnitude $\mathrm{AC}$ voltage to the motor to achieve the aims of variable speed operation ${ }^{[6]}$. The most common AC drives today are based on sinusoidal pulse-width modulation SPWM. Both voltage source inverters and current source inverters are used in adjustable speed AC drives. However, voltage source inverters with constant Volts/Hertz (V/f) are more popular, especially for applications without position control requirements, or where the need for high accuracy of speed control is not crucial.
Ideally, by keeping a constant V/f ratio for all frequencies the nominal torque-speed characteristic of the induction motor can be reproduced at any frequency. In this case, the stator flux, stator current and torque will be constant at any frequency. The great majority of variable-speed drives in operation today are of this type. However, since the introduction of fieldoriented control theory, almost all research has been concentrated in this area and little has been published about constant $\frac{V}{f}$ operation. Its practical application at low frequency is still challenging, due to the influence of the stator resistance and the necessary rotor slip to produce torque ${ }^{[7]}$. In addition, the nonlinear behavior of the pulse-width modulated voltage-source inverter in the low voltage range makes it difficult to use constant $\frac{V}{f}$ drives at frequencies below $3 \mathrm{~Hz}^{[8]}$.

The performance of induction motor operating at constant $\frac{V}{f}$ ratio can be improved by using different techniques, such as stator resistance compensation, slip compensation and vector compensation. The stator resistance compensation method consists of boosting the stator voltage by the magnitude of the currentresistance voltage drop. Slip compensation results in increasing the operating frequency. Vector compensation requires measurement of both voltage

Corresponding Author: Hussein Sarhan, Department of Mechatronics Engineering, Faculty of Engineering Technology, Al-Balqa' Applied University, Amman, Jordan 
and current and accurate knowledge of machine inductances $^{[7]}$.

The objective of this study was to develop new techniques to improve the performance of inverterinduction motor drive system with constant $\frac{V}{f}$ controller. For this purpose, two improving techniques are presented. The first technique is based on keeping the maximum torque constant for all operating frequencies and equals to its value at nominal frequency. The second technique is based on maintaining the magnetic flux constant at all operating frequencies and equals to its nominal value. The proposed techniques are validated by simulation and experimental results. It is shown that large torques are obtained, even in the low frequency range, with significantly reduced steady-state error in speed.

Modeling system components: The block diagram of inverter-three-phase squirrel cage induction motor is presented in Fig. 1. It consists of IGBT-inverter-based AC-to-AC converter, three-phase squirrel cage induction motor and controller. In order to analyze the system performance, all of these components should be modeled (mathematically described).

Modeling of the IGBT-inverter-based AC to AC converter: The inverter-based AC-to-AC converter is considered to be an ideal system, where the DC voltage at the input of the inverter has no $\mathrm{AC}$ component and the output voltage of the filter at the output of the inverter has no harmonics. For sinusoidal pulse width modulation SPWM, the ratio of the amplitude of the sinusoidal waveform to the amplitude of the triangular waveform is called the modulation index $m$, which can be in the range of 0 to $1^{[5]}$. The stator voltage $V_{s}$ can be defined as:

$V_{s}=m V_{n}$

where $V_{n}=$ nominal value of stator voltage.

The frequency of the stator voltage $f$ equals the frequency of the sinusoidal input waveform $f_{i n}$.

$f=f_{\text {in }}$

Varying the modulation index and the sinusoidal waveform frequency will change the RMS value of the stator voltage and frequency, respectively. Eqs. 1 and 2 constitute the steady-state model of inverter, shown in Fig. 2.

Modeling of controller: The controller with $V / f=$ constant must apply the following function:

$m=\left\{\begin{array}{cc}K f, & 0<f<f_{n} \\ 1, & f \geq f_{n}\end{array}\right.$

where $K=1 / f_{n}$ and $f_{n}=$ nominal frequency. The model of $V / f=$ constant controller is shown in Fig. 3 .

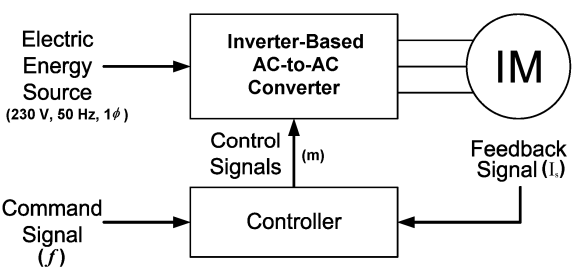

Fig. 1: Block diagram of inverter-three-phase squirrel cage induction motor

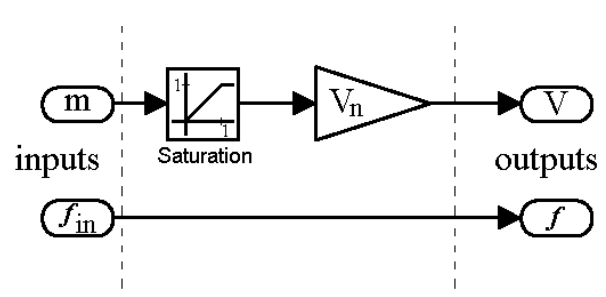

Fig. 2: Steady-state model of inverter

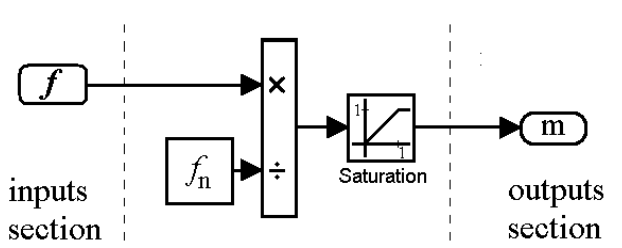

Fig. 3: The model of $V / f=$ constant controller

Modeling of three-phase squirrel cage induction motor: Based on the flux linkages and voltages equations, the electrical model of the squirrel cage three-phase induction motor with respect to a synchronously rotating $d-q$ coordinates can be expressed as ${ }^{[2,9]}$ :

$$
\begin{aligned}
& v_{d s}=R_{1} i_{d s}+L_{s s} \dot{i}_{d s}-\omega_{s} L_{s s} i_{q s}-\omega_{s} L_{m} i{ }^{\prime}{ }_{q r} \\
& v_{q s}=R_{1} i_{q s}+L_{s s} \dot{i}_{q s}+L_{m} \dot{i}_{q r}^{\prime}+\omega_{s} L_{s s} i_{d s}+\omega_{s} L_{m} i^{\prime}{ }_{d r} \\
& 0=R_{2}{ }_{2} i_{d r}{ }_{d r}+L_{r r}{ }_{r r} \dot{i}_{r d}{ }^{\prime}+L_{m} \dot{i}_{d s}-\left(\omega_{s}-\omega_{r}\right) L_{r r}{ }_{r r} i_{q r}{ }^{\prime}-\left(\omega_{s}-\omega_{r}\right) L_{m} i_{q s} \\
& 0=R_{2}^{\prime} i_{q r}^{\prime}+L_{r r}^{\prime} \dot{i}_{q r}^{\prime}+L_{m} \dot{i}_{q s}+\left(\omega_{s}-\omega_{r}\right) L_{r r}^{\prime} i_{d r}^{\prime}+\left(\omega_{s}-\omega_{r}\right) L_{m} i_{d s}
\end{aligned}
$$

The mechanical model of an induction motor can be represented by ${ }^{[2]}$ :

$$
\left.\begin{array}{l}
T_{e}=\frac{3}{4} P L_{m}\left(i_{q s} i^{\prime}{ }_{d r}-i_{d s} i_{q r}{ }^{\prime}\right) \\
\dot{\omega}_{m}=\frac{3}{4} \frac{P L_{m}}{J} i_{q s} i_{d r}{ }^{\prime}-\frac{3}{4} \frac{P L_{m}}{J} i_{d s} i^{\prime}{ }_{q r}-\frac{1}{J} T_{m}
\end{array}\right\}
$$

\section{Nomenclature}

$\psi_{d s}=\mathrm{d}$-axis component of the stator flux linkage, $\mathrm{Wb}$

$\psi_{q s}=\mathrm{q}$-axis component of the stator flux linkage, $\mathrm{Wb}$

$\psi_{d r}^{\prime}=\mathrm{d}$-axis component of the rotor flux linkage referred to the stator, $\mathrm{Wb}$

$\psi_{q r}^{\prime}=$ q-axis component of the rotor flux linkage referred to the stator, $\mathrm{Wb}$

$v_{d s}=\mathrm{d}$-axis component of the stator voltage, $\mathrm{V}$ 
Am. J. Appl. Sci., 3 (8): 1961-1966, 2006

$v_{q s}=\mathrm{q}$-axis component of the stator voltage, $\mathrm{V}$

$i_{d s}=\mathrm{d}$-axis component of the stator current, $\mathrm{A}$

$i_{d q}=\mathrm{q}$-axis component of the stator current, $\mathrm{A}$

$i_{d r}{ }_{d r}=\mathrm{d}$-axis component of the rotor current referred to the stator, A

$i^{\prime}{ }_{q r}=\mathrm{q}$-axis component of the rotor current referred to the stator, A

$L_{s}=$ stator inductance, $\mathrm{H}$

$L_{r}^{\prime}=$ rotor inductance referred to the stator, $\mathrm{H}$

$L_{m}=$ mutual inductance between rotor and stator, $\mathrm{H}$

$L_{s s}=L_{s}+L_{m}, \mathrm{H}$

$L_{r r}^{\prime}=L_{r}^{\prime}+L_{m}, \mathrm{H}$

$\omega_{s}=$ stator electrical angular speed, $\mathrm{rad} / \mathrm{s}$

$\omega_{r}=$ rotor electrical angular speed, $\mathrm{rad} / \mathrm{s}$

$\omega_{m}=\frac{2}{P} \omega_{r}$, rotor mechanical angular speed, $\mathrm{rad} / \mathrm{s}$

$P=$ number of poles

$T_{e}=$ electromagnetic torque, N.m

$T_{m}=$ load torque, N.m

$J=$ equivalent moment of inertia, $\mathrm{kg} \cdot \mathrm{m}^{2}$

The state-space model of induction motor in standard form, with respect to a synchronously rotating d-q coordinates, can be derived from Eqs. 4 and 5 as:

$$
\left.\begin{array}{l}
\dot{\mathrm{x}}=\mathrm{Ax}+\mathrm{Bu} \\
\mathrm{y}=\mathrm{Cx}+\mathrm{Du}
\end{array}\right\}
$$

where the matrix quantities in Eq. 6 are as follows:

$$
\begin{aligned}
\dot{\mathbf{x}} & =\left[\begin{array}{lllll}
\dot{i}_{d s} & \dot{i}_{d r}^{\prime} & \dot{i}_{q s} & i_{q r}^{\prime} & \dot{\omega}_{m}
\end{array}\right]^{T} ; \mathbf{x}=\left[\begin{array}{llllll}
i_{d s} & i_{d r}^{\prime} & i_{q s} & i_{q r}^{\prime} & \omega_{m}
\end{array}\right]^{T} \\
\mathrm{Y} & =\left[\begin{array}{llllll}
i_{d s} & i_{d r}^{\prime} & i_{q s} & i_{q r}^{\prime} & \omega_{m} & T_{e}
\end{array}\right]^{T} ; \quad \mathrm{u}=\left[\begin{array}{lllll}
v_{d s} & 0 & v_{q s} & 0 & T_{m}
\end{array}\right] ; \\
\mathrm{D} & =\left[\begin{array}{lll}
0]
\end{array}\right.
\end{aligned}
$$$$
\mathbf{A}=\left[\begin{array}{ccccc}
\omega_{s}+\frac{P}{2} \omega_{m} K_{2} & \frac{P}{2} \omega_{m} K_{1} \frac{L_{m}}{L_{s s}} & \frac{R_{1}}{L_{s s}} K_{1} & -\frac{R_{2}^{\prime}}{L_{m}} K_{2} & 0 \\
\frac{R_{1}}{L_{s s}} K_{1} & -\frac{R_{2}^{\prime}}{L_{m}} K_{2} & -\omega_{s}-\frac{P}{2} \omega_{m} K_{2} & -\frac{P}{2} \omega_{m} K_{1} \frac{L_{m}}{L_{s s}} & 0 \\
-\frac{P}{2} \omega_{m} K_{1} \frac{L_{m}}{L_{r r}^{\prime}} & \omega_{s}-\frac{P}{2} \omega_{m} K_{1} & -\frac{R_{1}}{L_{m}} K_{2} & \frac{R_{2}^{\prime}}{L_{r r}^{\prime}} K_{1} & 0 \\
-\frac{R_{1}}{L_{m}} K_{2} & \frac{R_{2}^{\prime}}{L_{r r}^{\prime}} K_{1} & \frac{P}{2} \omega_{m} K_{1} \frac{L_{m}}{L_{r r}^{\prime}} & -\omega_{s}+\frac{P}{2} \omega_{m} K_{1} & 0 \\
-\frac{\alpha L_{m} i_{q r}^{\prime}}{J} & 0 & \frac{\alpha L_{m} i_{d r}^{\prime}}{J} & 0 & 0
\end{array}\right]
$$$$
\mathrm{B}=\left[\begin{array}{ccccc}
\frac{K_{1}}{L_{s s}} & 0 & -\frac{K_{2}}{L_{m}} & 0 & 0 \\
0 & \frac{K_{1}}{L_{s s}} & 0 & -\frac{K_{2}}{L_{m}} & 0 \\
-\frac{K_{2}}{L_{m}} & 0 & \frac{K_{1}}{L_{r r}^{\prime}} & 0 & 0 \\
0 & -\frac{K_{2}}{L_{m}} & 0 & \frac{K_{1}}{L_{r r}^{\prime}} & 0 \\
0 & 0 & 0 & 0 & -\frac{1}{J}
\end{array}\right] ;
$$

Table 1: Induction motor data

\begin{tabular}{ll}
\hline Parameter & Value \\
\hline Stator resistance $R_{1}$ & $65 \Omega$ \\
Stator reactance $X_{1}$ & $40 \Omega$ \\
Mutual reactance $X_{m}$ & $241 \Omega$ \\
Rotor resistance referred to the stator $R_{2}$, & $25 \Omega$ \\
Rotor reactance referred to the stator $X_{2}$, & $30 \Omega$ \\
Nominal voltage $V_{n}$ & $230 / 400 \mathrm{~V}$ \\
Nominal torque $T_{n}$ & $1.3 \mathrm{n} . \mathrm{m}$ \\
Nominal input power $P_{n}$ & $0.25 \mathrm{~kW}$ \\
Nominal current $I_{n}$ & $0.76 \mathrm{~A}$ \\
Power factor cos $\varphi$ & 0.79 \\
Nominal frequency & $50 \mathrm{~Hz}$ \\
Number of poles $P$ & 4 \\
Nominal speed $n_{n}$ & $1455 \mathrm{rmp}$ \\
Nominal angular speed $\omega_{n}$ & $152 \mathrm{rad} / \mathrm{s}$ \\
Moment of inertia $J$ & $0.02 \mathrm{~kg} . \mathrm{m}^{2}$
\end{tabular}

$$
\begin{aligned}
C & =\left[\begin{array}{ccccc}
1 & 0 & 0 & 0 & 0 \\
0 & 1 & 0 & 0 & 0 \\
0 & 0 & 1 & 0 & 0 \\
0 & 0 & 0 & 1 & 0 \\
0 & 0 & 0 & 0 & 1 \\
-\alpha L_{m} i^{\prime}{ }_{q r} & 0 & \alpha L_{m} i_{d r}^{\prime} & 0 & 0
\end{array}\right] \\
\alpha & =\frac{3}{4} P ; K_{1}=\frac{L_{s s} L_{r r}^{\prime}}{L_{s s} L_{r r}^{\prime}-L_{m}^{2}} ; K_{2}=\frac{L_{m}^{2}}{L_{s s} L_{r r}^{\prime}-L_{m}^{2}}
\end{aligned}
$$

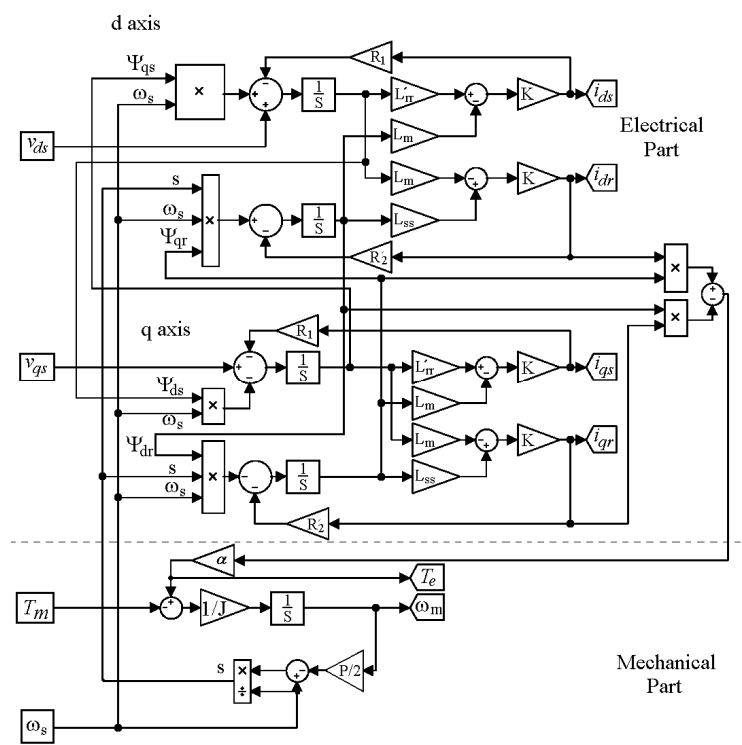

Fig. 4: State-space model of induction motor

The state-space model of induction motor according to Eq. 6 is represented in Fig. 4. The validity and correctness of the derived model were checked by comparing its response to that of the embedded MATLAB model. Both models gave identical responses with relative error of $0.01 \%$ under the same conditions. The parameters of simulated induction motor are given in Table 1.

The complete model of the drive system studied using MATLAB Simulink is shown in Fig. 5. 


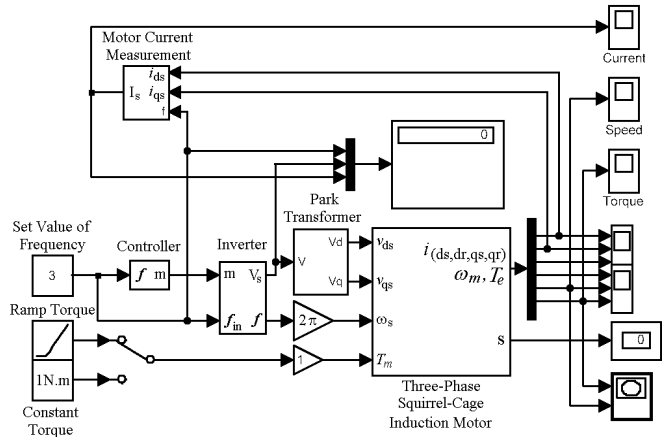

Fig. 5: The model of the drive system

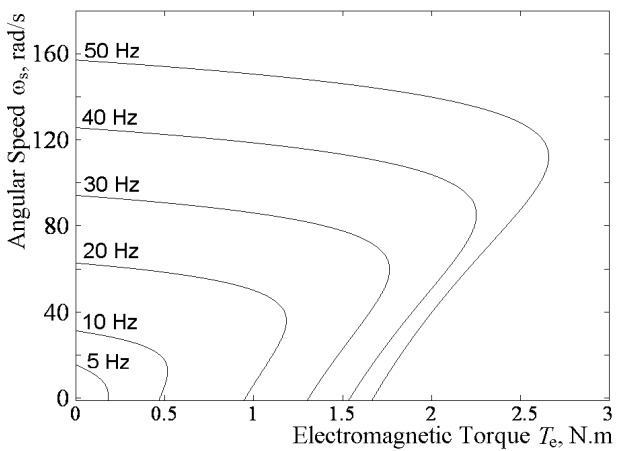

Fig. 6: Mechanical characteristics of drive system with $V / f=$ constant controller

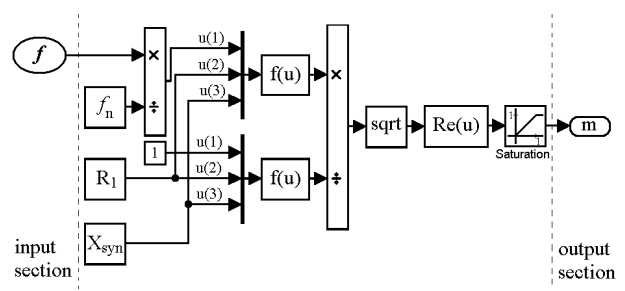

Fig. 7: The model of $T_{\max }=$ constant controller

Performance analysis of the drive system with $\frac{V}{f}=$ const controller was provided for different values of frequency and load torque. Examples of mechanical characteristics of the system at different frequencies are shown in Fig. 6. The results showed that both the starting torque and maximum torque decrease by decreasing the frequency. The motor was not able to start at frequencies below $22 \mathrm{~Hz}$ at load of $1.0 \mathrm{~N}$.m and below $11 \mathrm{~Hz}$ at load of $0.5 \mathrm{~N}$.m. It was noticed also, that the absolute slip $S_{a}$, defined as:

$s_{a}=\frac{\omega_{o}-\omega_{m}}{\omega_{o n}}$

decreased by decreasing the frequency, where $\omega_{o}$ is the no-load speed at a given frequency and $\omega_{o n}$ is the no-load speed at nominal frequency. In order to improve the starting and load performance of the drive system, a new controller is required.

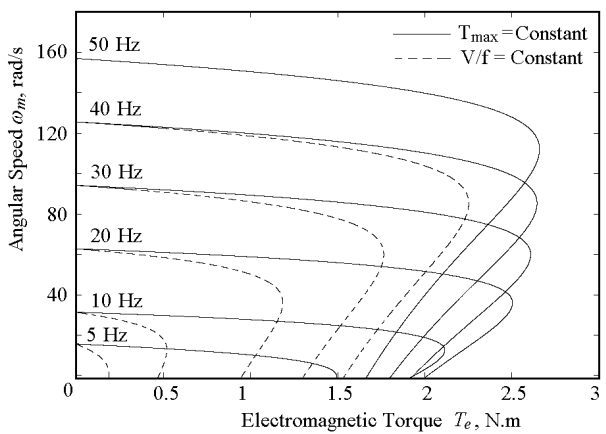

Fig. 8: Mechanical characteristics of drive system with $T_{\max }=$ constant controller

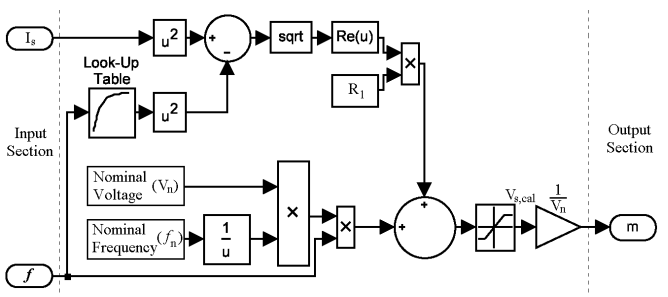

Fig. 9: The model of $\phi=$ constant controller

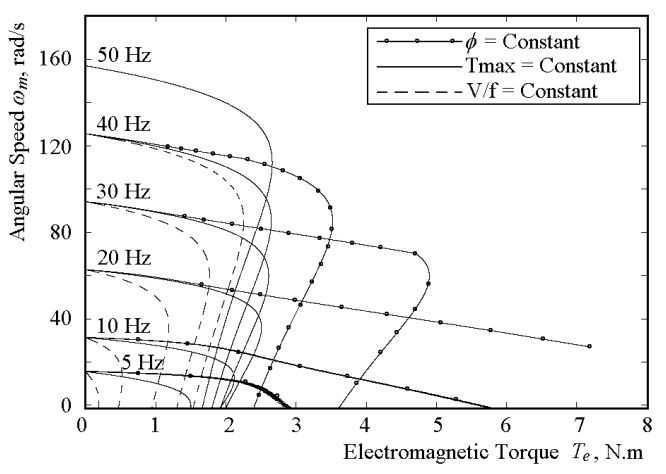

Fig. 10: Mechanical characteristics of drive system with different types of controllers

Improving performance of drive system: The performance of the drive system can be improved by using a controller that keeps the maximum torque $T_{\max }=$ constant or the flux $\phi=$ constant at any frequency $f$.

Controller with constant maximum torque: The maximum torque at nominal frequency $T_{\max (n)}$ can be determined by the following equation ${ }^{[6]}$ :

$T_{\max (n)}=\frac{3 P V_{n}^{2}}{8 \pi f_{n}\left(R_{1}+\sqrt{R_{1}^{2}+X_{\text {syn }}^{2}}\right.}$

where $V_{n}=$ nominal value of stator voltage (phase), $f_{n}=$ nominal frequency and $X_{\mathrm{syn}}=X_{1}+X_{2}^{\prime}=2 \pi f_{n}\left(L_{s}+L_{r}^{\prime}\right)$

The maximum torque $T_{\max }$ at any frequency $f$ can be determined as:

$T_{\max }=\frac{3 P V^{2}}{8 \pi f\left(R_{1}+\sqrt{R_{1}^{2}+\left(2 \pi f L_{s}+2 \pi f L_{r}^{\prime}\right)^{2}}\right.}$ 


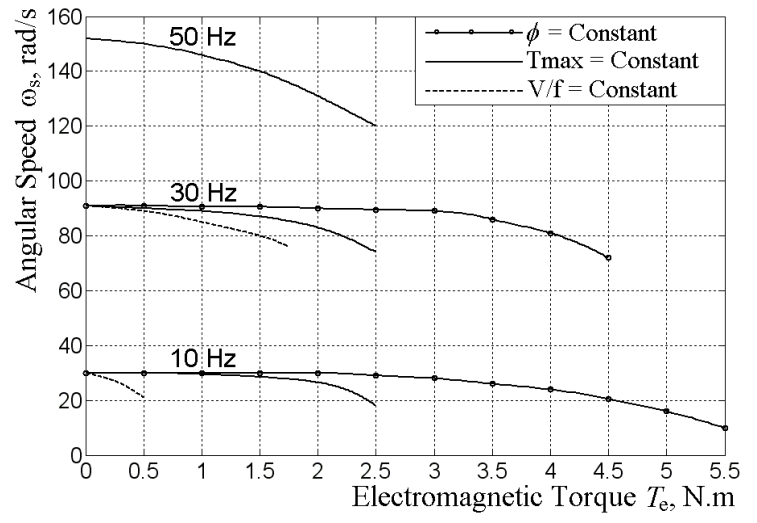

Fig. 11: Experimental mechanical characteristics of drive system with different types of controllers

Equating Eqs. 8 and 9 we get:

$m=\frac{V}{V_{n}}=\frac{f}{f_{n}} \sqrt{\frac{\frac{f_{n}}{f} R_{1}+\sqrt{\left(\frac{f_{n}}{f}\right)^{2} R_{1}^{2}+X^{2}{ }_{\text {syn }}}}{R_{1}+\sqrt{R^{2}{ }_{1}+X^{2}{ }_{\text {syn }}}}}$

Eq. 10 shows that the value of modulation index $m$ for controller with constant maximum torque is greater than that of controller with $\frac{V}{f}=$ constant.

The model of $T_{\max }=$ constant controller is shown in Fig. 7. The simulated mechanical characteristics of the drive system with $T_{\max }=$ constant controller are shown in Fig. 8, from which it is clear that the maximum torque remains constant for the frequency range from $20 \mathrm{~Hz}$ up to $50 \mathrm{~Hz}$. For frequencies below $20 \mathrm{~Hz}$ the maximum torque has been significantly increased comparing with that of the drive system with $\frac{V}{f}=$ constant controller. The absolute slip has been decreased. Analysis of simulated mechanical characteristics of the system with $T_{\max }=$ constant controller showed that the starting torque significantly increased and the motor successfully started at frequency of $4 \mathrm{~Hz}$ under $T_{m}=1.0 \mathrm{~N} . \mathrm{m}$ and $3 \mathrm{~Hz}$ under $T_{m}=0.5 \mathrm{~N} . \mathrm{m}$.

Controller with constant flux: The stator flux can be kept constant and equal to its nominal value, if the ratio of the magnetizing e.m.f. $E_{m}$ to the stator frequency $f$ remains constant, $\quad\left(\frac{E_{m}}{f}=\frac{E_{m n}}{f_{n}}=\right.$ constant $)$. Under this condition and based on the induction motor steady-state equivalent circuit and phasor diagram ${ }^{[7]}$, the stator voltage $V$ can be determined as:

$V=K_{V / f} f+R_{1} \sqrt{I^{2}{ }_{s}-I^{2}}$

where $K_{V / f}=\frac{V}{f}=$ constant, $I_{m}=$ magnetizing (no-load) current.
Eq. 11 shows that the stator voltage $V$ in the case of controller with constant flux is always greater than that of $\frac{V}{f}=$ constant controller. The model of controller with constant flux is shown in Fig. 9. Simulated mechanical characteristics of the drive system with different types of controllers are represented in Fig. 10, which shows that the decrease of frequency causes significant increase of maximum torque in the case of controller with constant flux. Fig. 10 also shows that the absolute slip reduced and became less than that of other types of controllers. The obtained mechanical characteristics of the drive system with constant flux controller are similar to those of drive system operating with constant power.

\section{RESULTS}

To verify the use of the proposed controllers with constant maximum torque and with constant magnetic flux, some experiments have been carried out with the same drive system that was simulated. The mechanical characteristics were obtained for different frequencies. Some of these characteristics are presented in Fig. 11. The experimental characteristics are similar to simulated characteristics, which means that the proposed techniques can be implemented in drive systems based on squirrel cage induction motors.

\section{CONCLUSION}

Based on the results of this study, the following conclusions can be made:

* The derived state-space model of three-phase squirrel-cage induction motor can be used to analyze the performance of induction motor drive systems.

* The implementation of constant maximum torque and constant flux controllers improve the mechanical characteristics of inverter-induction motor drive systems.

* The mechanical characteristics of the drive system with constant flux controller are harder than that with constant maximum torque controller.

* It is recommended to use constant maximum torque controller in drive systems operating with constant torque.

* It is recommended to use constant flux controller in drive systems operating with constant power.

\section{REFERENCES}

1. Leonhard, W., 1995. Controlled AC drives, a successful transfer from ideas to industrial practice. CETTI 95, Brazil, Sep.,11-12, pp: 1-12. 
2. Okogo, O.I., 2003. MATLAB simulation of induction machine with saturable leakage and magnetizing inductances. The Pacific J. Sci. Technol., 5: 5-15.

3. Fitzgerald, A.E. et al., 1990. Electric Machinery. 5th Edn. McGraw-Hill.

4. Marino, R., S. Peresada and P. Valigi, 1993. Adaptive input-output linearizing control of induction motors. IEEE Trans. Autom. Cont., 38: 208-221.

5. Zhou, K. and D. Wang, 2002. Relationship between space-vector modulation and three-phase carrier-based PWM: A comprehensive analysis. IEEE Trans. Industrial Electronics, 49: 186-195.

6. Bose, B.K., 1997. Power Electronics and Variable Frequency Drives. IEEE Press, pp: 402.
7. Alfredo, M.G., A.L. Thomas and W.N. Donald 1998. A new induction motor $\frac{V}{f}$ control method capable of high-performance regulation at low speeds. IEEE Trans. Ind. Applicat., 34: 813-820.

8. Sepe, R. and L. Lang, 1994. Inverter nonlinearities and discrete-time vector current control. IEEE Trans. Ind. Applicat., 30: 62-70.

9. Mohand, A.O., 2000. Simulation of direct fieldoriented controller for an induction motor using MATLAB-simulink software package. Proc. IASTED Intl. Conf. Modeling and Simulation, May 15-17, 2000-Pittsburgh, Pennsylvania, USA. 